\title{
Perspectiva bioética do modelo de assistência suplementar no Brasil
}

Regina R.P. Carvalho ${ }^{1}$, Paulo A.C. Fortes ${ }^{2}$, Volnei Garrafa ${ }^{3}$

\section{Resumo}

Este artigo apresenta os resultados de estudo voltado aos planos e seguros privados de saúde, denominado de assistência suplementar, regulamentados no Brasil há mais de uma década para solucionar conflitos na prestação de serviços. A partir de metodologia qualitativa descreveu-se e analisou-se o modelo de assistência, as questões resolvidas, as que permanecem e as que emergiram nesse período. Resultados mostram que o setor suplementar pouco avançou do modelo baseado na lista de doenças e procedimentos, aprovado como plano referência, aumentando os conflitos relativos à incorporação de tecnologias e ao incremento da demanda e dos custos, diante do envelhecimento populacional. Consolidaram-se políticas na regulamentação que ferem princípios bioéticos do Sistema Único de Saúde, na assistência aos mais vulneráveis, às gestantes e idosos. Falta regulação, por parte do Estado, na adequação da área suplementar com outras políticas públicas, no sentido de aperfeiçoar a qualidade da atenção e ampliar equitativamente a cobertura assistencial.

Palavras-chave: Brasil. Saúde suplementar. Bioética. Modelo de assistência. Serviços de saúde. Sistemas prépagos de saúde. Assistência à saúde.

\section{Resumen}

\section{Perspectiva bioética del modelo de asistencia suplementaria en Brasil}

Este artículo presenta los resultados de estudio dirigido a los planes y seguros privados de salud, denominado de asistencia suplementaria regulado en Brasil hace más de una década para resolver conflictos en la prestación de servicios. Desde una metodología cualitativa, se describió y se analizó el modelo de asistencia, las cuestiones resueltas, las que permanecen y las que emergieron en ese periodo. Los resultados muestran que el sector suplementario poco avanzó desde el modelo basado en la lista de enfermedades y procedimientos, aprobado como plan referencia, aumentando los conflictos relativos a la incorporación de tecnologías y al incremento de la demanda y de los costes ante el envejecimiento poblacional. Se consolidaron políticas en la reglamentación que hieren principios bioéticos contenidos en el Sistema Único de Salud, en la asistencia a los más vulnerables, a las gestantes y a los ancianos. Falta regulación, por parte del Estado, en la adecuación del área suplementaria con otras políticas públicas, en el sentido de perfeccionar la calidad de la atención y ampliar equitativamente la cobertura asistencial.

Palabras-clave: Brasil. Salud suplementaria. Bioética. Modelo de asistencia. Servicios de salud. Sistemas prepagos de salud. Prestación de atención de salud.

\section{Abstract}

\section{Bioethics perspective model supplemental assistance in Brazil}

This paper presents the results of a study about the private health plans and insurance, called supplementary health, which were regulated in Brazil more than a decade ago in order to solve conflicts in the provision of services. The model of care, the issues resolved, those that remain and the ones that emerged during this period were described and analyzed, using a qualitative methodology. The results show that the supplementary sector made little progress from the model based on the list of diseases and procedures, approved as a reference plan, increasing conflicts regarding the incorporation of technologies and the increase of the demand and costs, due to the aging of the population. Regulatory policies that hurt the bioethical principles contained in the National Health System were consolidated, mainly regarding the assistance to the most vulnerable, pregnant women and the elderly. Regulation is lacking, by the State, in the adequacy of the supplementary area with other public policies, in the sense of perfecting the quality of care and expanding healthcare coverage equitably.

Key words: Brazil. Supplemental health. Bioethics. Model of care. Health services. Health maintenance organizations. Delivery of health care.

Aprovação CEP FS/UnB nº 041/11

1. Doutora pariziregina@gmail.com - Instituto de Assistência Médica ao Servidor Público Estadual, São Paulo/SP, Brasil. 2. Livredocente pacfusp@usp.br-Departamento de Prática de Saúde Pública da Universidade de São Paulo, São Paulo/SP, Brasil. 3. Pós-doutor garrafavolnei@gmail.com - Cátedra Unesco e Programa de pós-graduação em Bioética da Universidade de Brasília, Brasília/DF, Brasil.

Correspondência

Regina Ribeiro Parizi Carvalho - Rua Coronel Lisboa, 515, Vila Mariana CEP 04020-040. São Paulo/SP, Brasil.

Declaram não haver conflito de interesse. 
Em 1998 o Brasil regulamentou os planos e seguros privados de assistência à saúde, que passaram a ser denominados de saúde suplementar ${ }^{1}$, com o objetivo de equacionar conflitos na prestação de serviços à população beneficiária, nas políticas de reajustes econômicos e no estabelecimento de regras para as empresas que atuam nesse mercado. O processo de regulamentação deu-se no lastro da Reforma Sanitária, da implementação do Sistema Único de Saúde (SUS) ${ }^{2}$ e da expansão dos debates bioéticos brasileiros, haja vista que vários atores sociais que militaram no processo da Reforma foram os mesmos que introduziram a bioética no Brasil ${ }^{3}$.

O período, desde a aprovação da regulamentação do setor suplementar, caracterizou-se pela expansão da globalização econômica, pelo aumento da participação privada na atenção à saúde em diversos países ${ }^{4,5}$, pelo avanço das ciências e da incorporação de biotecnologias na medicina, acompanhados, no Brasil, de mudanças econômicas e transição demográfica, com crescente envelhecimento da população ${ }^{6}$.

É nesse contexto que foi descrita e analisada a regulamentação que ocorreu no modelo assistencial suplementar brasileiro, de 1998 a 2010. Este trabaIho, sem a pretensão de esgotar a temática, procurou ampliar o debate sobre o modelo de assistência dos planos e seguros privados, utilizando como fundamentação a bioética de intervenção (BI) ${ }^{7}$, que preconiza a aplicação de referenciais éticos, sobretudo o da equidade, como princípio norteador de políticas e programas, seja no setor público ou privado, com a perspectiva de alcançar um horizonte mais igualitário nas condições de saúde da população.

\section{Método}

O trabalho foi desenvolvido em duas etapas. A primeira foi de revisão de dados, estudo da literatura e pesquisa documental, fundamentando o marco teórico-metodológico ${ }^{8}$ e a estratégia da pesquisa das seguintes categorias de análise sobre a regulamentação do setor suplementar: marco regulatório, questões normativas, assistenciais, administrativo-operacionais, econômico-financeiras, opinião dos atores sociais, panorama internacional e questões bioéticas.

A segunda etapa caracterizou-se por pesquisa exploratória de campo, com o objetivo de aprofundar e ampliar a representatividade das questões analisadas, elegendo a Câmara de Saúde Suplemen$\operatorname{tar}$ (CSS), da Agência Nacional de Saúde Suplemen- $\operatorname{tar}$ (ANS) ${ }^{9}$, como espaço privilegiado de participação no processo de regulamentação. Respeitando o critério de composição da Câmara, foi selecionada uma amostra de conveniência, com doze representantes de entidades, provenientes da área médica, da defesa do consumidor, de operadoras de planos de saúde, de prestadores de serviços, de entidades sindicais, do órgão regulador e do controle social do SUS. Foram apresentadas aos entrevistados questões contidas nas categorias de análise retromencionadas, como temas do roteiro de entrevista, permitindo a livre manifestação dos mesmos.

O conjunto teórico de dados e da pesquisa de campo foram analisados considerando os fundamentos metodológicos que reconhecem os desafios desses caminhos para o conhecimento, do vínculo entre o sujeito e o objeto de pesquisa e da necessidade de superação do debate dicotômico entre pesquisa qualitativa e quantitativa ${ }^{8}$. Nesse sentido, foram tomadas como referência as ideias de Habermas ${ }^{10}$, que analisa a linguagem como núcleo central do conhecimento, enfatizando a necessidade de estudo do contexto e de observação da práxis, pois diante da falta de transparência é preciso admitir a verdade como provisória. Tal medida é necessária posto que os atores envolvidos no processo - observador e observado - têm interesses, os quais mudam conforme a transformação dialética da realidade.

Em relação à bioética de intervenção ${ }^{7}$ foi considerada a importância do pensamento sistêmico e de análise da complexidade dos fenômenos na área da saúde, bem como a necessidade do estabelecimento de referenciais éticos - equidade, proteção e justiça - para a análise das informações coletadas na elaboração de políticas e programas que priorizem as pessoas mais necessitadas e vulneráveis, visando promover maior equilíbrio na saúde, diante das desiguais condições de vida das mesmas.

Ressalte-se, no entanto, que este trabalho faz parte de um estudo maior. Por razão de espaço, limita-se a apresentar apenas parte dos resultados obtidos com relação às questões assistenciais, a opinião dos atores sociais e as questões bioéticas.

\section{Resultado e discussão}

O modelo assistencial dos planos e seguros privados de saúde está previsto na Lei 9.656/98 ${ }^{1}$, tendo como referência a lista de doenças da Classificação Estatística Internacional de Doenças e Problemas Relacionados com a Saúde (CID), da Orga- 
nização Mundial da Saúde (OMS) ${ }^{11}$, bem como o rol de procedimentos de cobertura obrigatória ${ }^{12}$, que passaram a ser denominados de Plano Referência de Assistência à Saúde, dispostos no artigo 10 da referida lei, cuja oferta passou a ser condição mínima obrigatória para registro e funcionamento das operadoras no mercado de saúde suplementar no Brasil.

\section{A regulamentação do modelo assistencial}

Do período de 2002 a 2010 novas coberturas foram acrescentadas ao rol inicial, em função das atualizações científicas e tecnológicas na biomedicina. Esses incrementos diziam respeito tanto a novos procedimentos, incorporados na rotina assistencial em decorrência dos avanços tecnológicos, quanto por demanda da sociedade - caso dos procedimentos que tratavam do planejamento familiar ${ }^{12}$.

$O$ debate, conforme entrevistas com representantes da defesa do consumidor e do Conselho $\mathrm{Na}$ cional de Saúde (CNS), que participava da CSS, bem como a pressão para novas coberturas, sobretudo nas áreas de novas técnicas cirúrgicas, com inclusão de órteses, próteses e medicamentos, com frequência vem chegando ao Judiciário em busca de decisão para tais questões conflituosas. Esse movimento tem sido denominado de "judicialização do direito à saúde", em relação ao qual Scheffer ${ }^{13}$ analisou negativas de acesso às coberturas pelas operadoras, revelando que além das questões descritas também existem demandas relacionadas a procedimentos ainda não consolidados nos protocolos clínicos científicos ou autorizados pela Agência Nacional de Vigilância Sanitária (Anvisa).

Pesquisa realizada por Oliveira ${ }^{14}$ analisou demandas jurídicas por coberturas assistenciais, em um estudo de caso de uma operadora de autogestão, nos anos de 1998 a 2009, verificando o incremento de $23,8 \%$ das demandas jurídicas no período. Os motivos predominantes eram a realização de gastroplastias (cirurgia de obesidade), pagamentos de spas, implantação de órteses e próteses, medicamentos de alta complexidade, entre outros.

$\mathrm{O}$ rol ${ }^{12}$ de cobertura obrigatória dos planos, portanto, continua sendo um instrumento importante tanto para a população quanto para a regulação da ANS, pois facilita o acompanhamento das atualizações científicas, a fiscalização das restrições de cobertura e eventuais desvios de demanda, cujas questões foram centrais no processo que desencadeou a regulamentação dos planos e seguros, mas que ainda persistem no rol de reclamações sobre o setor no país. Em contrapartida, também é fato que estimula um modelo de assistência baseado no consumo de serviços, notadamente de maneira fragmentada e especializada, sem uma linha de orientação e cuidados, aumentando os custos na saúde, nem sempre associados à consequente melhoria nas condições de saúde dos assistidos.

Esse modelo de assistência à saúde tem sido discutido gradualmente na regulamentação, segundo manifestação do representante da ANS, pois predomina o que a Lei 9.656/98 estabeleceu como plano básico e mínimo que uma operadora deveria garantir no produto oferecido no mercado, além da opção segmentar de planos com cobertura ambulatorial/hospitalar, somente ambulatorial ou apenas hospitalar com atendimento pré-natal.

No entanto, a Resolução Normativa (RN) 139/06, aprovada pela ANS em 2006, alterou parte da lógica desse modelo ao instituir o Programa de Qualificação da Saúde Suplementar, introduzindo a avaliação de desempenho das operadoras de planos e seguros de saúde. Parte do programa é baseado na avaliação de indicadores de morbimortalidade do atendimento prestado aos beneficiários e no desenvolvimento de programas voltados para a promoção da saúde e prevenção de doenças ${ }^{15}$.

O programa foi introduzido em etapas, compondo um conjunto de indicadores que mede a qualidade da assistência prestada aos beneficiários/clientes da empresa e que são transformados em notas de desempenho para cada operadora, as quais são divulgadas anualmente aos órgãos de comunicação. $O$ debate sobre o modelo de atenção foi estimulado frente à ausência de programas de promoção à saúde e prevenção de doenças no setor suplementar, bem como de problemas relacionados ao diagnóstico tardio de neoplasias, sequelas de doenças crônicas e condutas clínicas questionáveis como o alto percentual de partos cirúrgicos (cesarianas), entre outras questões. Com relação às medidas, estas envolvem aspectos de compatibilização com diretrizes do SUS, de regulação das operadoras, de exercício profissional e da capacidade da rede assistencial no país.

De acordo com os entrevistados, outra questão relacionada com a qualidade da assistência foi o estabelecimento do convênio da ANS com as entidades médicas nacionais, intitulado Projeto Diretrizes ${ }^{16}$, cujo objetivo foi atualizar informações e recomendações sobre prevenção, diagnóstico, tratamento e controle das doenças listadas na CID, baseadas em evidências publicadas na literatura médica científica. A análise dos dados mostrou que até junho de 
2011 estavam disponibilizadas 82 diretrizes tratando de doenças, transtornos e agravos prevalentes na população. Embora em número bastante reduzido frente ao rol de doenças que fazem parte da CID, o instrumento também integrou o conjunto de medidas que visavam maior qualidade na prestação da assistência dentro do setor suplementar.

Estudo de caso de uma operadora de plano de saúde, realizado por Kanamura ${ }^{17}$, mostrou a magnitude dos gastos na assistência médico-hospitalar, particularmente quando associados a procedimentos que envolviam alta tecnologia, doença crônica e pessoas com mais de 70 anos de idade. Foram analisados os gastos mais elevados do ano de 2002, em relação ao qual o autor verificou que $36,2 \%$ dos recursos foram gastos com apenas $1 \%$ da população beneficiária do plano.

Questionamentos sobre esse modelo de atenção à saúde também foram apontados na tese de Hernandes ${ }^{18}$, em estudo longitudinal realizado entre 2000-2006 com 2.143 idosos, de 60 anos ou mais, com e sem plano de saúde no município de São Paulo. A autora concluiu que as associações encontradas com a variável dependente acima relacionaram-se mais às questões sociais, demográficas e de acesso aos serviços do que diferenças nas condições de saúde dos indivíduos que utilizavam a assistência pública ou privada. Nos resultados, também discute que a única enfermidade associada ou mais diagnosticada entre os titulares de planos e seguros privados, em relação aos que somente utilizavam o SUS, foi a osteoporose.

Assim, embora essas questões tivessem um custo direto nas despesas dos planos e custo indireto relativo ao volume de processos que tramitavam no Judiciário, não se verificou no período estudado outras iniciativas do órgão regulador, em conjunto com as operadoras, no sentido de realizar investimentos na área de avaliação do custo-benefício de incorporação dessas novas biotecnologias, como apontado em algumas entrevistas com operadoras de planos de saúde.

A ANS aprovou a RN 264/11 ${ }^{19}$ e a RN 265/11 20 com o objetivo de aumentar a adesão dos beneficiários às iniciativas de promoção da saúde e prevenção de doenças, criando mecanismos de incentivos pecuniários para os participantes dos programas. No entanto, faltam ações conjuntas nas políticas públicas que estimulem programas mais integrados, por exemplo, na área de Saúde do Trabalhador com o Ministério do Trabalho ou do Envelhecimento Ativo com o SUS/MS, entre outros.
A reflexão considera que a integração e adequação desses programas seriam aconselháveis, vez que mais de $70 \%$ dos beneficiários são de planos coletivos, nos quais os trabalhadores, em sua maioria, contam com serviços e programas distintos nas áreas assistenciais e de saúde do trabalhador, assim como não existem políticas específicas de preparação para a aposentadoria e da importância do envelhecimento ativo para as condições de saúde e qualidade de vida - questões consideradas prioritárias na agenda da central sindical entrevistada.

\section{Questões éticas do modelo assistencial}

Esse modelo fragmentado, baseado no consumo de serviços, sem o estabelecimento de uma linha de cuidados ao paciente, observado no modelo de assistência suplementar, mostra relação com o modelo de saúde denominado por Sfez ${ }^{21}$ como saúde perfeita. Este, segundo o autor, foi resultado de um estudo crítico desenvolvido para investigar "novas utopias" e realizado com as classes altas dos Estados Unidos, França e Japão, em 1997.

A pesquisa revelou que para essa camada da população as representações de saúde e de doença estavam vinculadas ao corpo e ao ecossistema, passíveis de correção mediante o crédito conferido aos novos conhecimentos na área da biotecnociência. Assim, o projeto genoma passou a representar a garantia, no futuro, da correção preventiva dos "corpos imperfeitos", enquanto os medicamentos de quarta geração poderiam assegurar a recuperação da saúde com um mínimo de efeitos indesejáveis.

Nesse modelo o indivíduo tornar-se-ia responsável pela manutenção e aperfeiçoamento do seu corpo em relação às dietas alimentares, aos exercícios físicos e aos cuidados com a pele, além de abandonar hábitos de vida considerados nocivos à saúde. Para tanto, as pessoas passariam a contar, para manutenção de uma aparência jovem e saudável, com um arsenal médico e de serviços como clínicas estéticas e reparadoras, academias de ginásticas e emagrecedoras.

$\mathrm{O}$ interesse nesse projeto, segundo $\mathrm{Sfez}^{21}$, não dizia respeito apenas à população, mas também à indústria de biotecnologias nas áreas de medicamentos, de órteses, de próteses e outros insumos que fazem parte do complexo industrial da saúde, bem como dos planos e seguros privados, interessados em reduzir custos e aumentar lucros, e dos governos - com vistas a reduzir seus gastos orçamentários na saúde. 
Lehoux ${ }^{22}$, em 2002, avaliando a dificuldade em determinar o significado das práticas médicas somente no plano clínico, ressaltou que o maior desafio está em analisar as tensões existentes entre o valor mercadológico das tecnologias em saúde; aquilo que os produtores reportam, uma vez introduzidas no mercado, o valor clínico, ou seja, o que elas propiciam a partir do conhecimento e da prática dos profissionais de saúde e o valor social, as transformações positivas e negativas advindas de sua utilização.

Tais aspectos vêm sendo também aprofundados nas discussões bioéticas, especialmente sobre as políticas de incorporação dos novos conhecimentos biotecnocientíficos que têm aumentado a capacidade de intervenção "no nascer, no viver e no morrer" 22. Ao mesmo tempo em que emerge o debate acerca de novas tecnologias em saúde, autores latino-americanos ${ }^{23}$ desenvolveram uma corrente crítica - denominada bioética de intervenção voltada, sobretudo, a analisar a saúde nos países de média e baixa renda, apontando para a necessidade de se ampliar ainda mais o olhar, tanto para as questões emergentes, em função dos novos conhecimentos científicos, quanto para as questões persistentes, agravadas com as desigualdades geradas na expansão do processo econômico da globalização. Nesse sentido, Garrafa e Porto ${ }^{24}$ advertem que é necessário agregar no valor social dessas tecnologias a condição de acessibilidade às pessoas, de maneira que não se transformem em outro fator de desigualdade das condições de saúde, ampliando as iniquidades já existentes.

Todas essas questões vêm sendo cada vez mais determinantes nas políticas e regras assistenciais, que no setor privado também são compatibilizadas com o equilíbrio financeiro e a margem de lucro, o que pode gerar ainda mais desigualdades, conflitos e distinções na atenção à saúde. Essa afirmação corrobora as entrevistas realizadas com representantes de entidades, membros da CSS. Segundo os participantes, tais distorções ocorrem nas políticas da assistência suplementar, em relação às carências para utilização dos planos de saúde pelas gestantes, bem como no aumento de carências para doenças preexistentes e no agravamento do valor dos planos para idosos ou na interferência da autonomia dos profissionais, criando situações nem sempre compatíveis com os valores éticos e morais que a sociedade projeta na saúde.

Nessas entrevistas, em paralelo, as operadoras queixaram-se da crescente dificuldade em compatibilizar os interesses individuais de utilização dos serviços com a sustentabilidade financeira coletiva do plano de assistência, diante do grau de incorporação de tecnologia na medicina e do aumento da demanda decorrente do envelhecimento, levando à diminuição e concentração do mercado de planos e seguros. Nesse sentido, Habermas ${ }^{10}$ traz uma discussão central sobre situações de conflitos aparentemente inconciliáveis, alegando que todos os atores têm interesses e esses devem ser explicitados nas arenas de debates. Argumenta que as verdades são provisórias diante de cenários em constante transformação e, consequentemente, de mudanças de interesses. Assim, é importante que os espaços de interlocução permitam a explicitação desses interesses, a maior transparência possível das informações e a dinâmica de acordos provisórios e reavaliáveis, dado que as verdades e os interesses também são provisórios.

Aplicando o argumento habermasiano à luz da $\mathrm{BI}$, pode-se dizer que nesses espaços é fundamental que o Ministério da Saúde (MS) assuma seu papel regulador, explicitando as diferenças de interesses, disponibilizando informações confiáveis, promovendo os acordos possíveis. Além disso, e sobretudo, seu papel institucional deve ser o de compatibilizar as atividades do setor privado suplementar, coordenado institucionalmente por meio da ANS, com as diretrizes éticas do SUS. Os princípios e diretrizes do Sistema são conquistas cidadãs, aprovadas pela população, em consonância com as pautas das organizações multilaterais. Estes pressupostos são discutidos na $\mathrm{BI}^{7,24,25}$ que aponta a necessidade de políticas eficazes na proteção dos mais vulneráveis.

Cabe considerar que a Bl está focada nas parcelas mais vulneráveis da coletividade, caracterizando esses setores da população não apenas em decorrência do menor poder aquisitivo, mas, também, como consequência da exposição a condições de maior fragilidade - tal como ocorre com crianças, gestantes, idosos, pessoas com deficiências, entre outros. Assim, para essa corrente da bioética as condições sociais adversas não podem ser objeto de negociação, em relação a fatores que possam aumentar a condição de fragilidade. Sob tal ótica, a BI coaduna-se com os princípios constitucionais que asseguram que a saúde é um direito do cidadão e dever do Estado, que tem sua assistência financiada pela população mediante contribuição de impostos ao poder público ou pagamento ao setor privado, tanto para diminuir os riscos de agravos à saúde como para contribuir com a dignidade da vida humana.

Por fim, é importante trazer para a discussão conceitual um critério fundamental, defendido no 
âmbito dos princípios do SUS no que concerne à BI: a equidade. O mundo, com tantas diferenças e desigualdades entre pessoas e povos, demanda aplicação de princípios que possibilitem abranger a diversidade. A equidade, instrumento conceitual que permite equacionar a desigualdade sem eliminar as diferenças, é um dos poucos critérios que se reveste dessa capacidade. Conforme ressalta Almeida ${ }^{26}$, a noção de equidade tem sido aplicada com diferentes entendimentos, pois se trata de conceito polissêmico que reflete valores e escolhas de uma dada sociedade, em um determinado momento histórico.

A importância central do conceito equidade no campo da bioética, bem como suas distintas interpretações, foi reafirmada em estudo realizado por Fortes ${ }^{27}$, em 2010. Entrevistando estudiosos brasileiros, apontou cinco ideias centrais sobre equidade, sendo que a mais expressiva, constatada no estudo e também defendida pela $\mathrm{BI}$, foi a do tratamento diferenciado diante de condições e necessidades desiguais que se apresentam para as pessoas, com o objetivo de alcançar um horizonte mais igualitário, almejado na saúde.

No entanto, a implementação da equidade em políticas e programas de saúde exige constante monitoramento, avaliação e discussão dialética dos resultados encontrados, haja vista que sua aplicação ocorre em cenários determinados por permanente transformação. Tais cenários e atores, por sua vez, sofrerão outras alterações com a implementação das medidas de equidade, podendo resultar em distorções, como o aumento das desigualdades, que deverão, então, ser avaliadas e corrigidas pari passu no decorrer da trajetória.

\section{Posição das organizações}

A equidade, conceito empregado pela $\mathrm{BI}$ e mais expressivo nos estudos de Fortes, tem se expandido geograficamente no campo da saúde, como no SUS, tendo sido o princípio homologado entre todos os países-membros da Unesco ${ }^{28}$, em 2005, na Declaração Universal sobre Bioética e Direitos Humanos, que na alínea (i), inciso b do artigo 14 sobre Responsabilidade Social e Saúde, trata de forma equitativa a questão da assistência como o acesso a cuidados de saúde de qualidade e a medicamentos essenciais.

Diante dos organismos internacionais o Brasil vem reiterando seu compromisso com a saúde como direito fundamental e equitativo, viabilizado mediante políticas públicas e/ou privadas que promovam melhores condições de vida e inclusão social. Reconhecendo também ser necessário o acesso a cuidados de saúde de qualidade e a medicamentos essenciais, equitativamente para os grupos mais vulneráveis da população (mulheres e crianças), que traduzem em si a essencialidade da vida.

Assim, as regras de regulamentação da assistência suplementar, como, por exemplo, carências e agravamentos de valores financeiros para atendimento de gestantes e crianças, deveriam ser submetidas, pela ANS, à compatibilização com os princípios e diretrizes do SUS, pois o fato de ser modalidade de serviço privada não confere autonomia em relação aos preceitos aprovados para a saúde na Constituição brasileira.

No caso específico da regulamentação da assistência suplementar, também é necessário que haja espaço na agenda regulatória para pontos que favoreçam a discussão dos conflitos e dos aspectos bioéticos que fazem interface com as questões assistenciais. Pois, como ficou evidenciado nas entrevistas com membros da CSS neste estudo, a abordagem pontual e resoluções restritas à esfera técnica e administrativa não têm concorrido para diminuir conflitos, promover melhor assistência e aperfeiçoar a lei.

O SUS e a ANS podem e devem aprofundar o debate em relação ao modelo de atenção, buscando qualificar a relação público-privada entre o SUS e o setor de assistência suplementar. Diante do agravamento dos problemas, essas instâncias de implementação da política de saúde precisam definir e aplicar regras claras em relação a toda prestação de serviços privados, não se limitando às intervenções pontuais e fragmentadas. A melhor governança desses setores, no entanto, exige diretriz e meta, que no Brasil devem concorrer, prioritariamente, para a universalização do acesso à saúde.

A OMS ${ }^{29}$, em 2012, tratou o financiamento e a cobertura universal da saúde como temas prioritários. Sua análise aponta que, anualmente, cerca de 150 milhões de pessoas no mundo dependem do pagamento do próprio bolso, na hora do atendimento, para garantir a assistência. Destes, 100 milhões são empurrados para baixo da linha da pobreza exatamente em decorrência desses gastos.

Esse cenário vem determinando um grande número de pessoas desassistidas, quadro que provavelmente será agravado na crise econômica dos países europeus. Os problemas econômicos naquele continente têm estipulado copagamentos às pessoas no momento do atendimento, inclusive no setor público. A gravidade da situação é revelada pelo significativo número de famílias falidas devido aos gastos privados com a assistência à saúde. 
A OMS aponta que a forma de pré-pagamento, quer para o setor público, mediante tributos, quer para o privado, por mensalidades, ainda é a melhor forma de financiamento da saúde, pois além de permitir melhor condição de compatibilização com os orçamentos familiares evita a submissão das pessoas a sofrimentos adicionais na hora do atendimento. Conforme a Organização, essa modalidade de pagamento tende a diminuir a vulnerabilidade do paciente, no momento do tratamento ou internação, dado que os serviços já foram financiados de antemão, antes mesmo da manifestação da doença.

Os custos da saúde também têm sido pauta dos debates em relação aos orçamentos públicos. A OMS estima que o desperdício de recursos esteja entre $20 \%$ a $40 \%$ do total empregado. A grande incorporação de tecnologia, o envelhecimento populacional e o modelo de atenção baseado no consumo excessivo de serviços diagnósticos e terapêuticos mais complexos têm levado ao encarecimento, sem precedentes, da assistência.

A bioética, como a $\mathrm{BI}$, tem se mostrado uma ferramenta essencial nos debates dos sistemas de saúde, pois ao tratar de questões pontuais tem a capacidade de estender a análise para temas mais gerais, mantendo coerência com princípios éticos e, ao mesmo tempo, permitindo a discussão do contraditório, que, conforme Habermas ${ }^{10}$, nada mais é que a outra face da mesma razão. A universalização do acesso à assistência, na perspectiva da BI, é um princípio inegociável, vez que é essencial à vida. Portanto, interesses, conflitos e divergências devem ser expostos e debatidos, bem como proposições, repactuações e acordos realizados, pois são inerentes à vida humana, que, por sua vez, depende das condições de saúde.

Em paralelo, conforme já ressaltado, as questões aqui discutidas são parte de um estudo que analisou a regulamentação da assistência suplementar no Brasil, na década passada. Neste, foram analisadas outras categorias que interferem no modelo assistencial, como o marco regulatório que denominou o setor de saúde suplementar, mas que na prática é assistência e que não se dá de forma "suplementar", seja na maneira do financiamento, pois permite a renúncia fiscal, seja no desenvolvimento de ações assistenciais, pois duplica o acesso a determinados extratos da população, em relação à atenção prestada pelo SUS.

Outras questões analisadas, como as econômico-financeiras, as administrativo-operacionais e o panorama internacional, também interferem nessa relação. Pois ter a saúde na condição de negócio, com previsibilidade de lucro (mercantilização), com concentração da rede de serviços no setor privado e nos estados mais desenvolvidos, bem como a internacionalização do capital financeiro nas empresas de saúde, certamente agravará conflitos de diferentes ordens, especialmente o modelo assistencial que - neste contexto - será cada vez mais padronizado conforme a lógica de negócio e lucro, independentemente das questões culturais e demandas próprias de saúde do país.

\section{Considerações finais}

A assistência suplementar no Brasil foi regulamentada há mais de uma década, mediante a aprovação da Lei 9.656/98, que atribuiu ao Estado o poder de registro, normatização e fiscalização dos planos e seguros privados de saúde no país. Isto possibilitou, no período de 1998 a 2010, avanços no estabelecimento de regras para atuação dessas operadoras, "saneando o mercado", aumentando as garantias contratuais e financeiras aos consumidores, o fluxo de informações e o controle operacional sobre as empresas.

O setor, no entanto, pouco avançou do modelo assistencial referenciado na lista de doenças e procedimentos que não o previsto em lei ou por demanda da própria sociedade. Estudos têm apontado os altos custos e a ausência de diferenças significantes, do modelo, no impacto das condições de saúde das pessoas que utilizam o setor público ou privado, embora este último conte com maior financiamento e melhor acesso aos serviços e às novas tecnologias.

Essa forma de assistência, embora facilitadora do acompanhamento e fiscalização da cobertura dos serviços ofertados pelas operadoras de planos e seguros privados de saúde, também tem estimulado a implementação de modelo de assistência baseado no consumo de serviços complexos e fragmentados, estimulando o processo de "judicialização" da assistência à saúde, diante da negativa ou da falta de previsibilidade de cobertura.

A ANS vem instituindo programas de qualificação da saúde suplementar, introduzindo novos cuidados no plano assistencial, mas com resultados ainda incipientes. De maneira geral, constata-se que faltam políticas de avaliação e incorporação de biotecnologias e maior integração com outras políticas públicas, como as relacionadas ao mundo do trabaIho e ao processo de envelhecimento.

No campo bioético, sobretudo da BI, o entendimento é de que o MS deve assumir seu papel 
de regulador maior da saúde, inclusive em relação à ANS, compatibilizando o modelo da assistência suplementar com os princípios e diretrizes do SUS. Esse processo promoveria maior adequação às políticas e programas do SUS, especialmente na proteção dos mais vulneráveis, como crianças, gestantes, idosos, entre outros. Isto concorreria, inclusive, para reafirmar seus compromissos em nível internacional, junto às organizações multilaterais.

O modelo de atenção à saúde é fundamental para a $\mathrm{BI}$, pois traz consequências no financiamento da saúde, na organização da prestação dos serviços, na participação público-privada da assistência e na incorporação de biotecnologias. Todos e cada um destes aspectos devem ser discutidos a partir do princípio da equidade, com o objetivo de universalizar o acesso à assistência à saúde, que é expectativa maior da sociedade.

Por fim, com o agravamento da crise na assistência à saúde em diversos países, decorrente da crise econômica, das questões demográficas, do encarecimento da incorporação tecnológica, além dos problemas persistentes em países de baixo e médio desenvolvimento, é fundamental que o Brasil e suas organizações discutam esse cenário, o modelo de atenção e a forma de financiamento, bem como deva ocorrer a participação e a regulação da relação entre o setor público e o privado no SUS.

\section{Referências}

1. Brasil. Lei $n^{\circ}$ 9.656, de 3 de junho de 1998. Dispõe sobre os planos e seguros privados de assistência à saúde. Diário Oficial da União. 4 jun. 1998:Seção I, p. 1.

2. Brasil. Lei $n^{\circ} 8.080$, de 19 de setembro de 1990 . Dispõe sobre as condições para a promoção, proteção e recuperação da saúde, a organização e o funcionamento dos serviços correspondentes e dá outras providências. [Internet]. Diário Oficial da União. 20 set. 1990 [acesso 25 fev. 2009]:Seção I, p. 18055. Disponível: http://www.planalto.gov.br/ccivil 03/Leis/L8080.htm

3. Porto D, Garrafa V. A influência da reforma sanitária na construção das bioéticas brasileiras. Ciênc Saúde Coletiva. 2011;16(1 Suppl):719-29.

4. Maarse H. The privatization of health care in Europe: an eight-country analysis. J Health Polit Policy Law. 2006;31(5):981-1014.

5. Drechsler $D$, Jütting J. Different countries, different needs: the role of private health insurance in developing countries. J Health Polit Policy Law. 2007;32(3):497-534.

6. Instituto Brasileiro de Geografia e Estatística. Pesquisa nacional por amostras de domicílios Pnad. [Internet]. Brasília: IBGE; 2009 [acesso 19 fev. 2011]. Disponível: http://www.ibge.gov.br/ home/estatistica/pesquisas/pesquisa_resultados.php?id_pesquisa $=40$

7. Garrafa V, Porto D. Intervention bioethics: a proposal for peripheral countries in a context of power and injustice. Bioethics. 2003;17(5-6):399-416.

8. Minayo MCS. O desafio do conhecimento: pesquisa qualitativa em saúde. $12^{\mathrm{a}}$ ed. São Paulo: Hucitec; 2010. p. 407.

9. Brasil. Agência Nacional de Saúde Suplementar. Câmara de Saúde Suplementar. [Internet]. Brasília: ANS; 2011[acesso 15 ago. 2012]. Disponível: http://www.ans.gov.br/index.php/participacao-dasociedade/camara-de-saude-suplementar

10. Habermas J. Dialética e hermenêutica: para a crítica da hermenêutica de Gadamer. Porto Alegre: LPM; 1987.

11. Organização Mundial da Saúde. Classificação estatística internacional de doenças e problemas relacionados com a saúde - CID. 2010 [acesso 4 maio 2011]. Disponível: http://www.fsp.usp.br/ $\mathrm{cbcd} /$

12. Brasil. Agência Nacional de Saúde Suplementar. Resolução Normativa $n^{\circ} 211$, de 11 de janeiro de 2010. Atualiza o rol de procedimentos e eventos em saúde, que constitui a referência básica para cobertura assistencial mínima nos planos privados de assistência à saúde, contratados a partir de $1^{\circ}$ de janeiro de 1999, fixa as diretrizes de atenção à saúde e dá outras providências. [Internet]. [acesso 20 maio 2011]. Disponível: http://www.ans.gov.br/index2.php?option=com_legislacao\& view=legislacao\&task=TextoLei\&format=raw\&id $=1840$

13. Scheffer MC. Os planos de saúde nos tribunais: uma análise das ações judiciais movidas por clientes de planos de saúde, relacionadas à negação de coberturas assistenciais no Estado de São Paulo [dissertação]. São Paulo: USP; 2006.

14. Oliveira JAD. Demandas jurídicas por coberturas assistenciais - estudo de caso: Cassi [dissertação]. São Paulo: USP; 2010.

15. Brasil. Agência Nacional de Saúde Suplementar. Resolução Normativa $n^{\circ} 139$, de 24 de novembro de 2006. Institui o programa de qualificação da saúde suplementar. [Internet]. [acesso 29 maio 2011]. Disponível: http://www.ans.gov.br/index2.php?option=com_legislacao\&view=legislacao \&task=TextoLei\&format=raw\&id=1121

16. Brasil. Agência Nacional de Saúde Suplementar. Diretrizes clínicas na saúde suplementar [Internet]. ANS; 2000 [acesso 29 maio 2011]. Disponível: http://www.projetodiretrizes.org.br/ ans/ 
17. Kanamura AH. Gastos elevados na assistência médico-hospitalar de um plano de saúde. [dissertação]. São Paulo: Universidade de São Paulo/Faculdade de Medicina; 2005.

18. Hernandes ESC. Idosos com e sem plano de saúde no município de São Paulo: estudo longitudinal, 2000-2006 [tese]. São Paulo: USP; 2011.

19. Brasil. Agência Nacional de Saúde Suplementar. Resolução Normativa $n^{\circ} 264$, de 19 de agosto de 2011. Dispõe sobre promoção da saúde e prevenção de riscos e doenças e seus programas na saúde suplementar. [Internet]. [acesso 2 fev. 2012]. Disponível: http://www.ans.gov.br/index2. php?option=com_legislacao\&view=legislacao\&task=TextoLei\&format=raw\&id=1795

20. Brasil. Agência Nacional de Saúde Suplementar. Resolução Normativa $n^{\circ}$ 265, de 19 de agosto de 2011. Dispõe sobre a concessão de bonificação aos beneficiários de planos privados de assistência à saúde pela participação em programas para Promoção do Envelhecimento Ativo ao Longo do Curso da Vida e de premiação pela participação em programas para população-alvo específica e programas para gerenciamento de crônicos. [Internet]. [acesso 2 fev. 2012]. Disponível: http:// www.ans.gov.br/index2.php?option=com_legislacao\&view=legislacao\&task=TextoLei\&format=r aw\&id=1796

21. Sfez L. La santé parfaite: critique d'une nouvelle utopie. Paris: Seuil; 1997.

22. Lehoux P. Une analyse critique de la valeur dês techologies et dês processus innovants: peut-elle nous amener à concevoir de nouveaux instruments de regulation? Montréal: Université de Montréal; 2002.

23. Berlinguer G. Questões de vida: ética, ciência, saúde. Salvador: APCE; 1993. p. 218.

24. Garrafa V, Porto D. Bioética de intervención. In: Tealdi JC, director. Diccionario latino americano de bioética. Bogotá: Unesco; 2008. p. 161.

25. Garrafa V. Da bioética de princípios a uma bioética interventiva. Rev. bioét. (impr.) 2005;13(1):12534.

26. Almeida C. Equidade e reforma setorial na América Latina: um debate necessário. Cad Saúde Pública. 2002;18(Suppl):23-36.

27. Fortes PAC. A equidade no sistema de saúde na visão de bioeticistas brasileiros. Rev Assoc Med Bras. 2010;56(1):47-50.

28. Organização das Nações Unidas para a Educação, a Ciência e a Cultura. Declaração Universal sobre Bioética e Direitos Humanos. [Internet]. Paris: Unesco; 2005 [acesso 4 maio 2011]. Disponível: http://unesdoc.unesco.org/images/0014/001461/146180por.pdf

29. Organização Mundial da Saúde. Financiamento dos sistemas de saúde: o caminho para a cobertura universal. Relatório Mundial de Saúde. 2010 [acesso 4 maio 2011]. Disponível: http:// www.who.int/whr/2010/whr10_pt.pdf

\section{Participação dos autores}

Regina R.P. Carvalho realizou, na condição de doutoranda, a pesquisa que originou o artigo, que também escreveu e revisou. Paulo AC Fortes participou da revisão crítica do trabalho, contribuindo nas adequações para a formulação final. Volnei Garrafa participou da concepção, delineamento e revisão crítica na condição de orientador da tese e do artigo.

Recebido: 19. 4.2013

Revisto: 5. 7.2013

Aprovado: 15. 7.2013 